This is an Accepted Manuscript of an article published by Taylor \& Francis in Perspectives : Policy and Practice in Higher Education on 10/12/19, available online: https://www.tandfonline.com/doi/

full/10.1080/13603108.2019.1698475 


\title{
Creating Connections: Polymathy and the Value of Third Space Professionals in Higher Education
}

\author{
Aranee Manoharan \\ Careers and Employability Service, Kingston University London, United Kingdom \\ Kingston University, Penrhyn Road, Kingston upon Thames, Surrey KT1 2EE \\ a.manoharan@kingston.ac.uk
}

\section{Bionote - Aranee Manoharan}

Aranee taught within HE before moving into professional services, where she has practiced within the areas of student experience and engagement, community affairs, inclusion, employability, and curriculum enhancement. She is a Fellow of the Higher Education Academy and a qualified professional development coach, who is certified in change management.

A keen advocate of diversity and inclusion, Aranee has volunteered for over 15 years on issues affecting BME and refugee communities, sits on her university's Race Equality Charter Group, and is a role model on the Advance HE's female leaders programme, Aurora. She also serves as a governor on the Kingston University Board of Governors, representing professional services staff and contributing to academic governance as well as monitoring the growth of the physical and virtual environment.

Alongside her work, Aranee is also completing a $\mathrm{PhD}$ in International Relations, researching how the underlying causes of protracted ethnic conflict in postcolonial societies can be better understood using an inter-disciplinary, levels of analysis framework that enables the development of more effective policy interventions. 


\section{Creating Connections: Polymathy and the Value of Third Space Professionals in Higher Education}

This think-piece explores the value of polymathic thinking as an alternative conception of mastery to the dichotomy between specialisation and generalisation, enabling universities to thrive within an increasingly turbulent policy environment. It posits that the polymathic approach of 'third space professionals' can provide and address the challenges of the modern university.

Keywords: blended professionals; creativity; higher education; innovation; keyshaped professionals; mastery; polymath; polymathy; polymathic thinking; professional hybrids; third space professionals; t-shaped professionals; unbounded professionals

\section{"A jack of all trades is a master of none, but oftentimes better than a master of one."}

Higher Education is an environment within which hyper-specialisation is revered. This reflects society's preoccupation with specialisation, which has been ongoing since the onset of the industrial revolution, where the economistic notion of breaking things down into their component parts was introduced into our psyches. Terjesen and Politis (2015:151) explain that "the university institution is largely monolithic and pathway dependent, perpetuating discipline-based scholarship and sometimes creating new niches that are even more specialized" and this veneration for expertise in a single field manifests not only in the research we conduct and the disciplinary programmes we teach, but also the services we provide. This creates a paradox within the university, as individuals are "incentivized to focus on a particular issue in a single discipline (...) and discouraged from developing deep expertise in multiple fields" when "real-life problems" of the university and the world "involve multiple dimensions" and "require a multidisciplinary skillset" (Terjesen and Politis, 2015:151). This reflects what Whitchurch (2008a:376) refers to as the 'twin-dynamic' of the university, "comprising of a process of increased functional specialisation on the one hand and a blurring of activity across professional locations on the other". Nevertheless, specialist knowledge is still regarded in the highest esteem, whilst the path of the generalist is often unfairly considered one of mediocrity.

Whilst the value of expertise in one field should not be disputed, we must also recognise that such a preoccupation is a contributing factor to the silo mentality that is pervasive in UK HE, as experts within different fields struggle to create connections and find common ground on broader, cross-institutional priorities of the university. As Jascha KaykasWolff, the CEO of Mozilla, explains this is not just an issue in HE:

"'There is a fundamental problem in business - organisations are very good at creating silos based on functional expertise" (...) they struggle to communicate both among themselves and within the wider business, leading to a lack of understanding, breeding suspicion" (KPMG, 2019).

In addition to a difficulty in communication, such specialised ways of working can also inhibit creativity, as Sadler-Smith, E. and McGurk, J. (2014: 8) explain, "in the Gestalt psychology view of problem-solving, prior knowledge and expertise can be a barrier to creativity" as "a downside of expertise is that it can give rise to 'tunnel vision', 'strategic myopia' or 'grooved thinking"'. A defining aspect of this 'grooved thinking', and the usthem conflict it creates within HE, is the longstanding dichotomy between 'academic' 
and 'non-academic' functions. Whitchurch and Law (2010:2) describe how "such divisions reflect a perceived split between 'collegial' approaches implying academic autonomy, and 'managerial' approaches (...) serving socio-economic goals, so that 'academic' and 'management' activity (...) become polarised". This polarisation hinders the collaborative practice between professional and academic knowledges required for universities to become agile and thrive in a turbulent policy environment. How then can connections be created between the different specialisms of the university? I posit that the growing force of third space professionals (Whitchurch, 2008b) and their polymathic approach to practice can show us the way.

\section{Third Space Professionals}

Third space professionals are those who reject the longstanding separation between academic and non-academic functions to perform 'blended' or hybrid roles, comprising elements of both academic and professional activity. This concept stems from the notion of the 'third space' (Bhaba, 2004), an environment in which different cultures, assumptions, and practices come together in critical engagement. It is a space "of resistance to conventional understandings, norms, and binaries" (Whitchurch, 2013:23), where professionals break through barriers created by the "different life worlds" (ibid.) that exist for the various responsibilities of the university, e.g. learning and teaching, research, widening participation. Third space professionals forego such occupational boundaries by navigating multiple 'life worlds' and disciplinary spaces within the university environment.

Taking a polymathic approach, third space professionals become fluent in multiple expert languages, understand different professional motivations, and are able to connect with a range of occupational dispositions. Whilst specialists thrive within the "distinctive culture" of their "epistemic community" (Henkel, 2010:8), targeting their work at standardised activities that are common to their field; the unbounded nature of their polymathic approach enables third space professionals to "enter messy (...) space (...) working with, rather than being challenged by, ambiguous conditions" (Whitchurch, 2008a:382). Such professional hybrids are able "to view organizational issues through "two-way windows" (Croft, Currie, and Lockett, 2015:380) and utilise their multiple expertise to "overcome "cognitive inertia' (Sparrow 2002)" as they are able to see "how various elements of the problem can be fitted together holistically in a new way that isn't reliant on an established way of seeing a problem" (Sadler-Smith, E. and McGurk, J. 2014:8). As such, third space professionals can navigate liminal spaces by borrowing from one area and applying it to a new context, working in "an exploratory way with tension (...) seeking common basis for understanding by (...) reconceptualising the space that they and others occupy" (Whitchurch, 2008a:382). The value of this multiplicity of knowledge and skillset cannot be underestimated, as third space professionals play a crucial role in creating connections between specialist areas, building common understanding, and driving interdisciplinary solutions. Such inter-disciplinary ways of working cannot be achieved through multi-disciplinary teams alone and Root-Bernstein (2003:275) makes the case that this multiplicity of knowledge "must be within the minds of individuals". Businessman, Charlie Munger, clarifies this further by explaining that, it requires an individual who can "understand the separate pieces of a particular scenario, and moreover, how the pieces come together to make sound business decisions" (Terjesen, S. and Politis, D., 2015:153). I believe that this argument can also be applied 
to professional practice within $\mathrm{HE}$, and it is this polymathic aptitude that third space professionals bring to the university environment.

\section{Polymathic Thinking}

The concept of polymathic thinking is best associated with the Renaissance period, exemplified by intellectuals such as Leonardo da Vinci, who were unconstrained by disciplines and explored many fields across the arts and sciences, discovering transdisciplinary solutions to the issues and challenges of their day. The defining feature of polymathy is the ability to have proficiency and expertise across multiple fields. It differs from notions of specialisation and generalisation through its focus on creating connections and examining the intersection of ideas to understand how different 'trades' link, overlap, impact or depend upon one another. It is in the connection and interconnections of these ideas, cultures, and people that creativity, opportunity, and innovation occurs.

Root-Bernstein (2003) and Terjesen and Politis (2015) summarise the importance of polymathy in their analysis of Nobel Prize winners, who exemplify the value of this approach in the modern era. For example, Esther Duflo and Abhijit Banerjee won the economic prize this year for their "experimental approach to tacking global poverty" (Nobel, 2019 cf. Sepehr, J. and Calderwood, I., 2019) that tries to address "the interconnected root of the problem" (Duflo, $2019 \mathrm{cf}$. Sepehr, J. and Calderwood, I., 2019). For polymathic thinkers such Duflo and Abhijit, solutions are found at the intersections and interconnections of issues and disciplines - whilst economists by trade, they achieved positive results in their work to alleviate poverty in Indian communities through the integration of economics with sociology, education, and public health. The pursuit of multiple fields can be misconstrued as a lack of direction, but as Nobel winner, Ramon y Cajal explains "to him who observes them from afar, it appears as though they are scattering and dissipating their energies, while in reality they are channelling and strengthening them" (Root-Bernstein, 2003:268). As such, polymathic thinking goes beyond singular specialisation to multiple-expertise and the use of this multi-knowledge to create. Such a capacity is imperative in a world amidst the Fourth Industrial Revolution (Schwab, 2016) and led by rapidly evolving disruptive technologies, where grand challenges, such as the climate crisis, clean growth, and an aging population, require holistic solutions. Therefore, a polymathic approach moves beyond the concept of the Tshaped professional who possesses deep disciplinary knowledge in one area along with an "ability to function as "adaptive innovators" (T-Academy, 2018), because as Bridgestock (2015) explains, "one downward stroke" i.e. one speciality "is nearly always insufficient". Instead, I posit that her concept of the 'Key-shaped professional', where individuals "possess several areas of disciplinary capability at different degrees of depth" keenly refers to the polymathic approach. As scholars have identified through their research in creativity, innovation, and polymathy, "possessing disciplinary knowledge and skills in multiple fields supports the ability to translate knowledge, collaborate, and work with others from dissimilar backgrounds and knowledge regimes" in addition to being able to provide "their own unique transdisciplinary perspectives that support creativity, innovation and problem-solving" (ibid.). This is why I believe we need to encourage and enable the development of polymathic thinkers (i.e. third space professionals) within the university. Such a cadre of multi-specialists will able to address challenges and advance progress by facilitating communication and understanding between HE specialisms and bringing distinct ideas and priorities into a cohesive whole. 


\section{Final Thoughts}

The nature of higher education has changed enormously over the past 25 years, as "the neoliberal notions of performativity, managerialism, massification, marketisation and corporatisation" have significantly impacted the 'doing' of university (Veles \& Carter (2019:2). This ongoing change necessarily means that the challenges faced by providers in the UK and beyond require more nuanced, inter- and trans-disciplinary solutions that can only be achieved through a polymathic approach.

If only certain people with a certain educational or experiential background do a certain job, creativity and innovation become muted, as a lack of diverse perspectives contribute to that area of work. By understanding and having experience of many fields, a professional can recognise how they interconnect, acknowledge dependencies, and identify ways in which change in one affects the other. It is important to recognise that such polymathic ways of thinking and being are not confined to 'great minds' and 'geniuses'. Education research (e.g. Bloom, 1985) tells us that "experts are made rather than born" meaning that each of us have the capacity "to develop deep expertise in multiple areas" (Terjesen and Politis, 2015:155) if we so choose. This approach to professional practice is no longer a 'nice to have' - it is the way forward. The dynamic nature of the Fourth Industrial Revolution and the grand challenges we face, in the university and society, mean it is now a necessity for professionals to have the capacity for multiple-expertise.

Therefore, I believe it is essential that universities embrace third space professionals, those who are already out there navigating multiple life-worlds and creating connections, and work with them to move the university beyond specialisation to foster a culture of resilience and agility through polymathy.

\section{References}

Bhabha, H. (2004) The Location of Culture. London: Routledge.

Bloom, B. S. (1985) Developing talent in young people. New York: Ballantine Books.

Bridgestock, R. (2015) "KEY-shaped people, not T-shaped people - disciplinary agility and 21st century work", Future Capable, July $18^{\text {th }} 2015$. Access on: 25/10/11.

Henkel, M. (2010) "Change and continuity in academic professional identities", in Gordon, G. and Whitchurch, C. (eds.) Academic and professional identities in higher education: The challenges of a diversifying workforce. Pp. 3-12. New York, NY: Routledge.

KPMG (2019) "How a not-for-profit firm took on the planet's most powerful tech giants", The Times Online. October $28^{\text {th }} 2019$. https://www.thetimes.co.uk/static/how-a-not-forprofit-firm-took-on-the-planets-most-powerful-tech-giants/ Accessed on: 05/11/2019.

Root-Bernstein, R. (2003) "The Art of Innovation: Polymaths and Universality of the Creative Process" in Shavinina, L. V. (2003) (ed) International Handbook on Innovation. Oxford: Pergamon. 
Sadler-Smith, E. and McGurk, J. (2014) Fresh thinking in learning and development, Part 3 of 3: Insight and Intuition. London:CIPD.

Schwab, K. (2016) The Fourth Industrial Revolution. London:Penguin.

Sepehr, J. and Calderwood, I. (2019) "Nobel Prize for Economics 2019 Awarded to 3 Pioneers for Their Fight Against Poverty", Global Citizen. October $14^{\text {th }} 2019$. https://www.globalcitizen.org/en/content/Nobel-Prize-for-Economics-povertyresearchers/ Access on: 29/10/2019.

T-Academy (2018) "What is the 'T'?", Michigan State University. http://tsummit.org/t Access on: 25/10/11.

Terjesen, S. and Politis, D. (2015) "From the Editors: In Praise of Multidisciplinary Scholarship and the Polymath", Academy of Management Learning and Education, Vol. 14 (2), pp. 151-157.

Veles, N. and Carter, M. (2016) "Imaging the Future: Changing the Landscape for Third space professionals in Australian Higher Education Institutions", Journal of Higher Education Policy and Management, Vol. 38(5), pp. 519-533.

Whitchurch, C. (2008a) "Beyond Administration and Management: Reconstructing the Identities of Professional Staff in UK Higher Education”, Journal of higher Education Policy and Management. Vol. 30(4), pp. 375-386.

Whitchurch, C. (2008b) "Shifting Identities and Blurring Bourndaries: The Emergence of Third Space Professional in UK Higher Education", Higher Education Quarterly, Vol. 62(4). Pp. 377-396.

Whitchurch, C. and Law, P. (2010) "Optimising the Potential of Third Space Professionals in UK Higher Education", Leadership Foundation for Higher Education.

Whitchurch, C. (2013) Reconstructing Identities in Higher Education: The Rise of 'Third Space' Professionals. London: Routledge. 